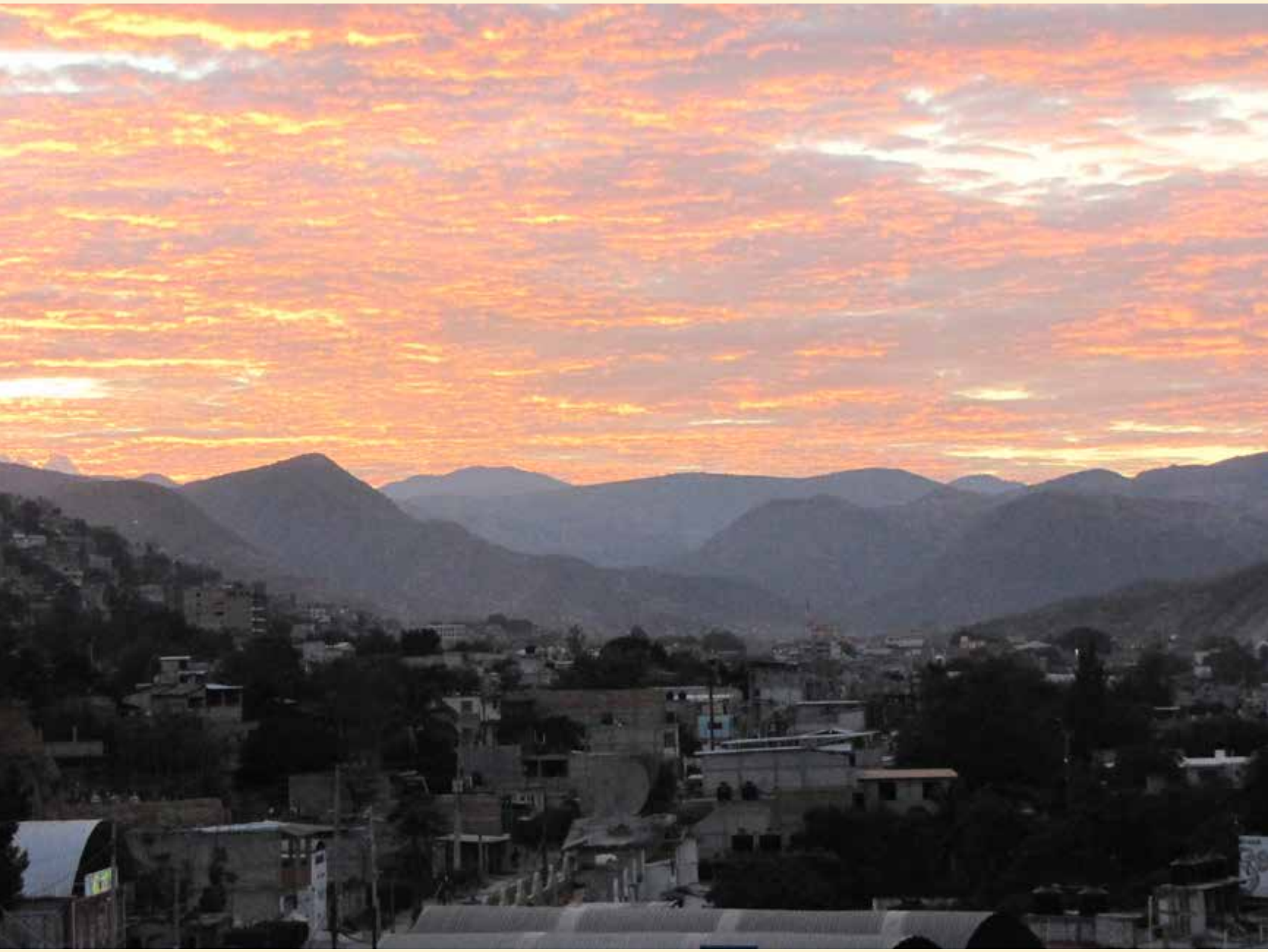

Imagen 1. "Así es la vida en la montaña: con el gris cotidiano del lamento. La pobreza de todo, a veces hasta de la esperanza. Y aquello que uno creía que podía ser el cielo, se convierte en un lugar con el alma en llamas...". Tlapa Gro. (11 de noviembre de 2009). De regreso de un recorrido por varias comunidades de la Montaña. Fotografía: Josefina Ramírez. 


\section{La guerra en el cuerpo. Experiencia de niñas y adolescentes de la Montaña de Guerrero en un internado de religiosas en México ${ }^{1}$}

The war in the body. Experience of girls and adolescents of the Mountain of Guerrero in a religious boarding school in Mexico // A guerra no corpo. Experiência de meninas e adolescentes da Montanha de Guerrero em um internato religioso no México

Josefina Ramírez Velázquez ${ }^{2}$

Escuela Nacional de Antropología e Historia, ENAH, México jos.ramirez.velazquez@gmail.com

Revista Corpo-grafías: Estudios críticos de y desde los cuerpos / Volumen 7 - Número 7 / Enero - diciembre 2020 / ISSN impreso 2390-0288, ISSN digital 2590-9398 / Bogotá, D.C., Colombia / $180-200$

(c) (1) (8) $\ominus$

Fecha de recepción: 15 de enero de 2019

Fecha de aceptación: 1 de mayo de 2019

DOI: https://doi.org/10.14483/25909398.15516

Cómo citar este artículo: Ramírez, J. (2020, enero-diciembre). La guerra en el cuerpo. Experiencia de niñas y adolescentes de la Montaña de Guerrero en un internado de religiosas en México. Revista Corpo-grafías: Estudios críticos de y desde los cuerpos, 7(7), pp 180-200 / ISSN 2390-0288.

\footnotetext{
Articulo de Investigación: El presente artículo deriva de la investigación titulada El trastorno psicogénico de la marcha como lenguaje del cuerpo. Explicación socio-antropológica de la realidad vivida en Villa de las Niñas, en Chalco, Estado de México, dirigida por la Dra. Josefina Ramírez Velázquez, y realizada entre 2009-2012. Investigación financiada por el Instituto Nacional de Antropología e Historia INAH. 3 Dra. En Antropología con especialización en Antropología Médica, por el Centro de Investigaciones y Estudios Superiores en Antropología Social (CIESAS). Coordinadora de la Línea de Investigación "Cuerpo y Poder" Posgrado de Antropología Física, ENAH. Miembro del SNI de CONACYT nivel II. Es profesora investigadora del posgrado de Antropología Física de la ENAH, México.
} 


\section{Resumen}

En el Estado de Guerrero, la pobreza y la falta de oportunidades configuran la vida cotidiana de la población. Para poder continuar sus estudios, muchas niñas de este estado se trasladaron a un internado de religiosas en otro Estado, y donde en 2007, surgió un brote epidémico de histeria colectiva o trastorno psicogénico. Basada en las narrativas de algunas niñas afectadas de la región de la Montaña de Guerrero, discuto en este artículo que, en la búsqueda de formación educativa, las niñas y adolescentes libran una guerra en el cuerpo que alude a la imbricación de la opresión de género y de etnia, con el uso y control de los cuerpos en encierro.

\section{Palabras clave}

Montaña de Guerrero; educación; cuerpo; opresión de género; trastorno psicogénico; internado religioso

\begin{abstract}
In the State of Guerrero, poverty and lack of opportunities configure the daily life of the population. In order to be able to continue their studies, many girls of this state, moved to a border school ruled by nuns in another state, and where in 2007, emerged an epidemic outbreak of mass hysteria. Based on the narratives of some girls affected in the region of la Montaña de Guerrero, I argue in this article that in the search for educative formation, girls and adolescents wage a war in the body that alludes to the overlapping of gender oppression and ethnicity, with the use and control of bodies in confinement.
\end{abstract}

\section{Keywords}

Montaña de Guerrero; education; body; gender oppression; mass psychogenic illness; religious boarding school

\section{Resumo}

No estado de Guerrero, a pobreza e a falta de oportunidades moldam o cotidiano da população. Para continuar seus estudos, muitas garotas desse estado mudaram-se para um colégio interno de religiosos em outro estado e, em 2007, surgiu um surto de histeria coletiva ou distúrbio psicogênico. Com base nas narrativas de algumas meninas afetadas na região da Serra de Guerrero, defendo neste artigo que na busca por formação educacional, meninas e adolescentes iniciam uma guerra no corpo que alude à imbricação da opressão de gênero e de etnia, com o uso e controle dos corpos em confinamento.

\section{Palavras-chave}

Montanha Guerreiro; educação; corpo; opressão de gênero; transtorno psicogênico; estágio religioso

Todas las fotos fueron tomadas por la Dra. Josefina Ramírez Ve lázquez, durante el trabajo de campo realizado en la Montaña de Guerrero en el periodo 2009-2011, para la investigación "El trastorno psicogénico de la marcha como lenguaje del cuerpo. Explicación socio-antropológica de la realidad vivida en Villa de las Niñas, en Chalco, Estado de México"

\section{Introducción}

El presente trabajo es un pequeño avance derivado de la investigación que tengo a mi cargo en la ENAH, titulado El trastorno psicogénico de la marcha como lenguaje del cuerpo. Explicación socio-antropológica de la realidad vivida en Villa de las Niñas, en Chalco, Estado de México.

Inicié esta investigación siguiendo tres ejes analíticos que dan forma a la antropología física crítica (Ramírez, 2010a). El primero hace referencia a una noción relacional del cuerpo y la enfermedad, abordados como constructos socioculturales. El cuerpo como asiento de la enfermedad es el terreno más inmediato dónde se expresan el poder, el sufrimiento y las contradicciones sociales, así como el sitio de resistencia personal y social. La enfermedad se entiende como metáfora codificada que constituye el lenguaje del cuerpo cuya comprensión precisa de actividades interpretativas que articulen biología, sociedad, cultura e ideología (Ramírez, 2010b). El segundo eje se funda en el paradigma centrado en el significado y situado etnográficamente. El tercero destaca la idea de que no hay actor sin contexto. 
La tesis central que empecé a manejar se orientó a explicar la enfermedad desde la significación sociocultural que la destaca como lenguaje del cuerpo y enuncia el punto de quiebre del ámbito social. Esto es, todos los síntomas que caracterizaron el trastorno psicogénico desde la biomedicina pueden interpretarse, desde la antropología, como expresiones de miedo y resistencia ${ }^{3}$ contra las múltiples violaciones a los límites corporales. Son actos de rebelión que simbolizan lo que no puede hablarse directamente, pero puede interpretarse como una renegociación de las obligaciones y derechos entre las autoridades y las alumnas.

Para explicar el brote de histeria colectiva definido como trastorno psicogénico de la marcha, ocurrido a más de 500 alumnas del internado en cuestión, me propuse describir y analizar el proceso físico, social, cultural y moral experimentado por las niñas que fueron diagnosticadas con dicho trastorno, a fin de construir explicaciones que, articulando el contexto familiar y el de la institución educativa, permitieran comprender la naturaleza del problema relacionado con padecimientos de salud mental en ellas. Tal enunciado da sentido a los ejes analíticos indicados arriba, y aunque el punto central del análisis es la experiencia de la enfermedad desde el punto de vista de quienes la sufrieron, como se podrá ver solo en la descripción de dicha experiencia aparecen indiscutiblemente distintos contextos significantes que le dan sentido y permiten comprender la compleja naturaleza de la misma, más allá de los marcos etiológicos que, desde la biomedicina, dan sentido al signo-construcción médico frente al síntoma-experiencia del paciente (Menéndez y Di Pardo, 1996). ${ }^{4}$

3 El concepto de resistencia ha sido usado por algunos antropólogos (Van Schaik, 1988; Ong, 1988; Dunk, 1989; Martin, 1992; Lock, 1993; Lock y Scheper-Hughes, 1996) para analizar la experiencia del padecimiento más estudiado como "posesión de espíritus," y su traducción "histeria," "somatización" y "trastornos de conversión". La idea que subyace es la de visibilizar los contextos de sufrimiento y las formas de agencia de los sujetos, en lugar de imponer el discurso médico dominante.

$4 \quad$ La enfermedad desde la perspectiva sociocultural ha dado cuenta de una doble dimensión: la que se construye desde la biomedicina y la que

\section{La realidad irrumpiendo en el pensamiento}

Una mañana de abril del 2007, en plena tranquilidad de los días de guardar de la Semana Santa, escuché en la radio que más de 500 alumnas del internado de religiosas Villa de las Niñas, ubicado en Chalco, Estado de México, fueron presas de una histeria colectiva caracterizada por síntomas como desmayos, mareos, fiebres, vómitos, dolores de cabeza y de articulaciones, así como dificultad para caminar y hablar.

La noticia me rebotó en la cabeza y no pude quitármela de encima pensando que, un evento como ese, tenía que ser explicado desde aquellos referentes analíticos que había venido construyendo, acentuando ahora con mayor énfasis la noción foucaultiana de cuerpo tensado por relaciones de poder y dominación (Foucault, 1977), y la de un contexto institucional, definido por Goffman (1994) como Institución total. Más allá de eso, me interesa reflexionar este acontecimiento como un espacio técnico que modela el yo, los cuerpos, sus maneras de habitar y de ser sujetos de experiencia. Supuse que, dentro de ese espacio, generado en el encierro, el cuerpo y las emociones son producidos, controlados y resignificados en pos de lograr un cuerpo disciplinado y dócil.

Inicié la investigación de manera informal, siguiendo minuciosamente toda la compleja información presentada por diversos medios informativos. Primero por pura curiosidad, después porque nada de ello me fue indiferente en lo académico, en lo moral y en lo personal.

Una amplísima base de datos hemerográficos construidos para documentar el caso me hizo ver que el primer

proviene de la experiencia del paciente. Los autores citados abordan ambas perspectivas haciendo la distinción desde las nociones: signo-construcción y síntoma-experiencia refiriéndose a dos mundos de saberes sobre la enfermedad que. Si bien, ambas nociones están en permanente transacción, a menudo la primera mantiene la hegemonía sobre la segunda. En la investigación, aunque doy cuenta de cómo la biomedicina define el trastorno psicogénico, mi interés central está en el síntoma-experiencia de las internas, en principio porque su voz fue acallada una vez que se dio el diagnóstico. 


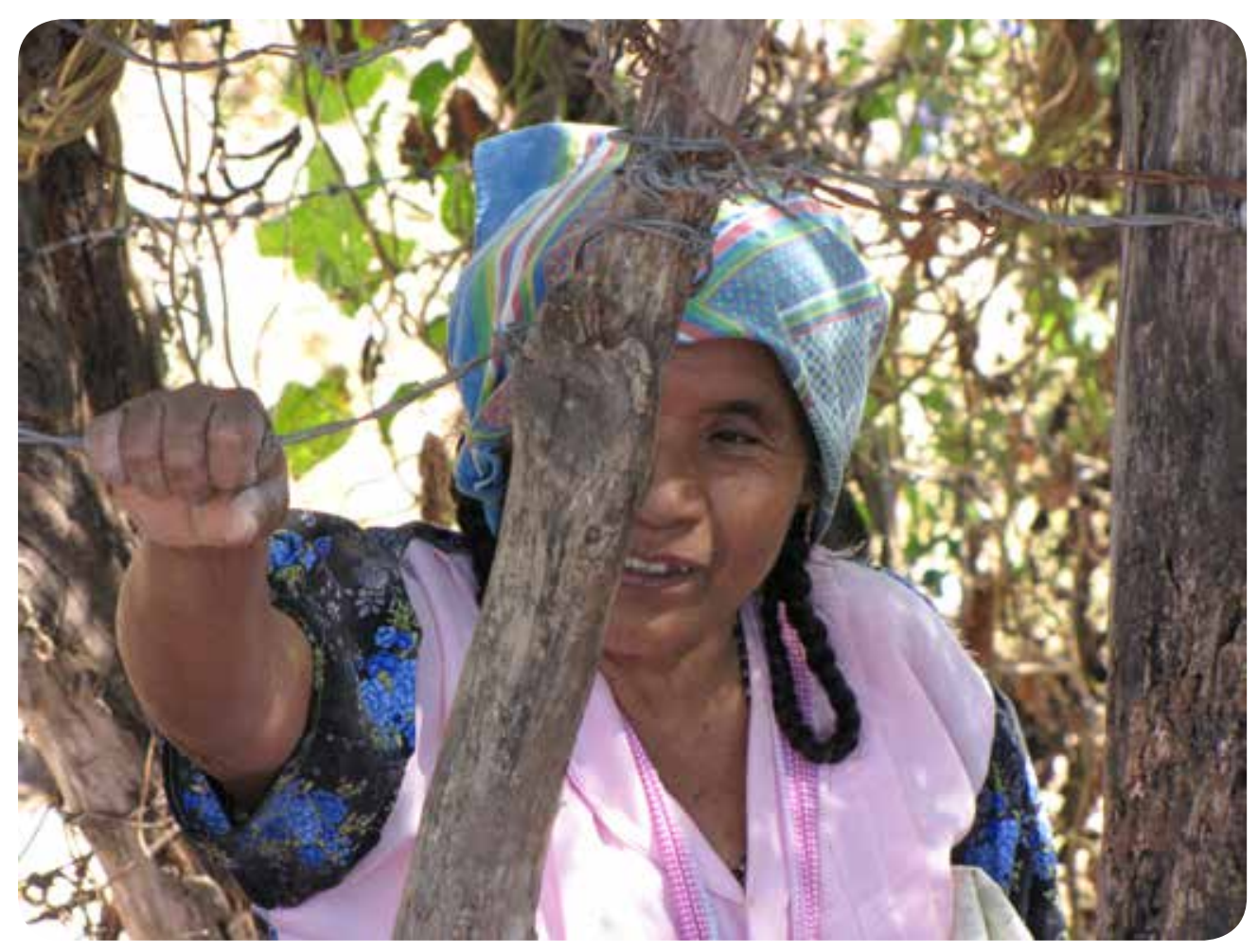

Imagen 2. Entre los cercos reales y metafóricos. Fotografía: Josefina Ramírez.

supuesto que apunta a explicar la enfermedad como respuesta al encierro y como producto de una Institución Total (Ramírez, 2009, 2013, 2014) fue corroborado de manera casi inmediata por la numerosa información que afloró durante la primera mitad del 2007, con una noticia que, escandalosa por sus efectos epidémicos, pronto fue convertida en nota controversial y se mantuvo durante meses en discusión e investigación por quienes se habían interesado por develar los abusos de poder de autoridades civiles o religiosas y velar por los derechos humanos de aquellos sujetos considerados vulnerables -léase niños y adolescentes, los más pobres, los que no tienen acceso a la educación, indígenas en su mayoría-.
Aparecieron testimonios sobre las condiciones del internado. Inicialmente se atribuyó el mal al posible contagio por comida en mal estado y agua contaminada. Se pensó en una posible brucelosis, en un contagio por estreptococo beta hemolítico, en leptospirosis o riquetsiosis. ${ }^{5}$ Más adelante, a partir de testimonios de profesores que laboraban ahí, se habló de fanatismo por parte de las religiosas de la Congregación de las Hermanas de María; del aislamiento de las chicas, que solo pueden tener contacto con el exterior dos veces al año; de la aplicación de códigos disciplinares parecidos a los de la milicia,

5 Consultar: Excelsior [en línea], 2 de abril de 2007; La Jornada [en línea], 18 de abril de 2007; 29 de marzo de 2007. 


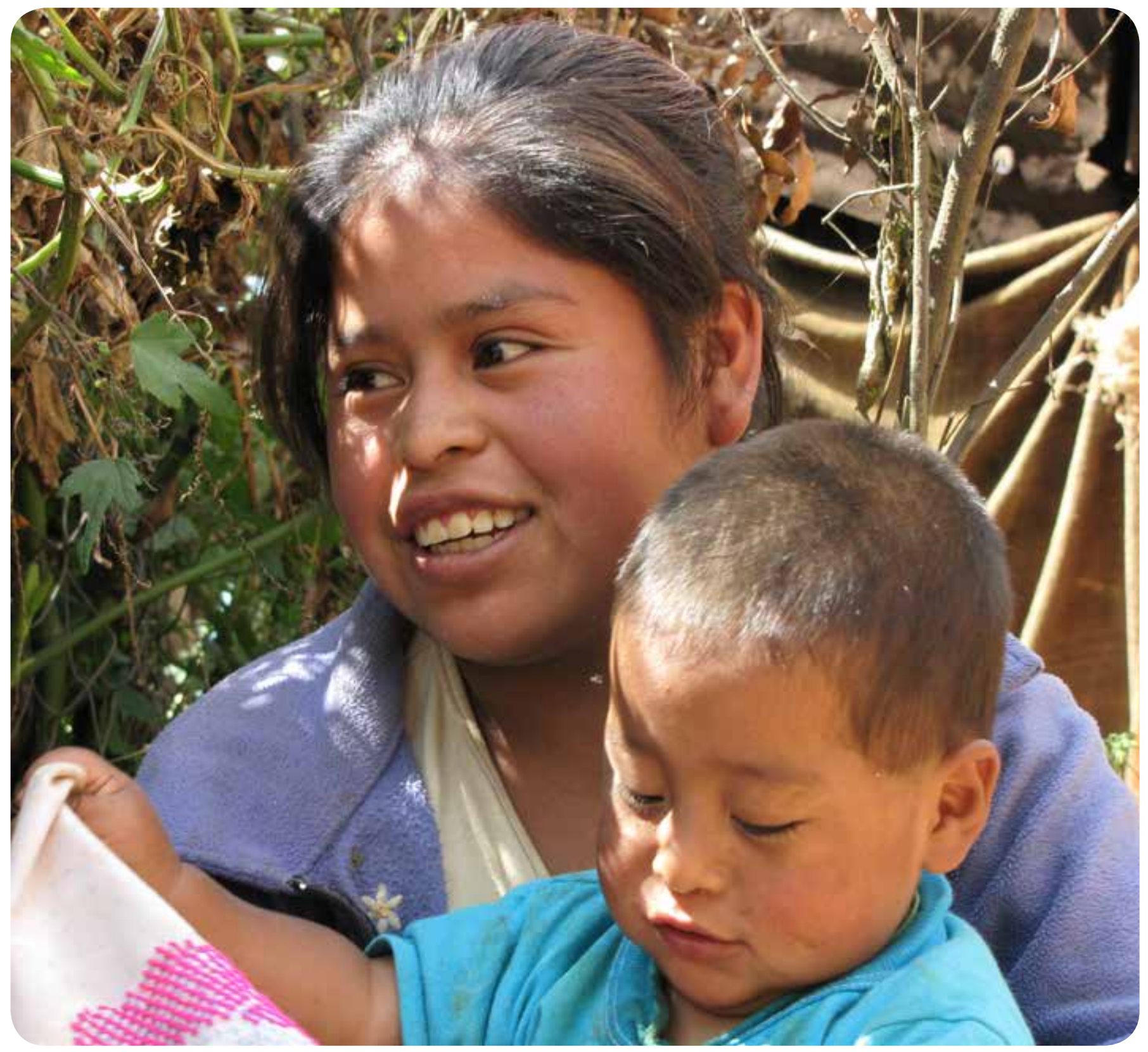

Imagen 3. Niña tlapaneca Madre soltera. Fotografía: Josefina Ramírez. 
de la vigilancia extrema sobre el cuerpo y las emociones (Ramírez, 2013, 2014); del control de los afectos, ya que se impide el contacto cercano entre alumnas y entre profesores y alumnas (Ramírez, 2012); de la censura de ciertos temas de contenidos políticos y sexuales en los temas de enseñanza de los profesores y, por último, de explotación laboral, ya que se decía que dentro del internado operaba una maquila de ropa.

En mayo de ese mismo año, tras las investigaciones realizadas por la Secretaría de Salud (SSA), (SSA) a través de epidemiólogos, médicos, paidopsiquiátras y psicólogos, se concluyó que lo que les pasó a las jóvenes no era una cuestión orgánica, sino psicológica definida como trastorno psicogénico de la marcha. ${ }^{6}$

El caso se cerró. No hubo medicalización ni seguimiento del problema, pero sí estigma: mayor marginación de las afectadas, exclusión y castigo por parte de las autoridades religiosas hacia aquéllas que, tras ser diagnosticadas positivamente y ser entrevistadas por diversos medios, hablaron de la situación de disciplina y control que sus cuerpos experimentaban en el encierro. ${ }^{7}$ Villa de las $\mathrm{Ni}$ ñas no se cerró, pero se volvió más hermética.

A partir de ese momento mi mirada se transformó en una aguda reflexión y acción, toda vez que el diagnóstico explicó la enfermedad desde el punto de vista médico psiquiátrico y convirtió la expresión del malestar, como lo ha apuntado Young (1982, p. 275), en un hecho deshistorizado y descontextualizado que culpabilizó a la propia víctima, al afirmarse que todo fue producto de su psique. De las niñas enfermas no se volvió a saber, no se les dio atención ni seguimiento de ningún tipo.

6 En rueda de prensa, el subdirector de Epidemiología de la Secretaría de Salud del Estado de México, informó que dicho trastorno "puede ser desencadenado por un estrés común, no es contagioso, ni es provocado por maltrato físico o por intoxicación."

$7 \quad$ El castigo que se les aplicó consistió en que nunca más les permitieron volver al internado y acabar sus estudios; tampoco se les dieron los documentos probatorios de tales estudios.

\section{El contexto de la histeria}

Por diversos medios intenté ser recibida por las religiosas directivas del internado a fin de hacer etnografía y entrevistarlas a ellas y a las chicas afectadas. Esa era la tarea legítima de todo interesado en hacer una investigación recurriendo al contexto y al actor de manera relacional, pero pronto me di cuenta de que esa postura metodológica resultaba ingenua ante el hecho mediático y político en el que se había convertido la histeria colectiva de la Villa de las Niñas de Chalco.

Así fue que, con datos secundarios provenientes fundamentalmente de varios periódicos y de sitios de internet donde se ofertaba el internado, me dediqué a reconstruir el contexto de la histeria. Ya iniciado el trabajo de campo, dicha reconstrucción se hizo a partir de la experiencia de las internas.

Villa de las Niñas, es una institución filantrópica religiosa que brinda educación secundaria técnica, bachillerato y algunos oficios a niñas de entre 12 y 17 años. Se oferta insistiendo que la educación, la habitación, la ropa y la alimentación son gratuitas y todo ello va destinado a la población más pobre, marginal y sin posibilidades de educación que tiene el país, población que lamentablemente es de origen campesino e indígena. La institución es dirigida por la congregación Hermanas de María, ${ }^{8}$ fundada en Corea.

En 1997, Villa de las Niñas se instaló en Chalco sobre una superficie de 32 hectáreas en donde se construyeron cuatro edificios de siete niveles. En esos inmuebles se ubican aulas y dormitorios, talleres, laboratorios, salas de cómputo y capillas. El gimnasio, la pista de carreras, los campos de juego, la alberca semiolímpica y los auditorios están rodeados de amplias áreas verdes llenas de flores. Sus instalaciones son austeras pero enormes, y por ello albergan a poco más de 4000 alumnas, atendidas por un

$8 \quad$ En ese momento la directora del plantel era la madre Yong Sook Cheong, mejor conocida como Margie Cheong. 
grupo de religiosas, algunas de ellas extranjeras (coreanas, filipinas, guatemaltecas y brasileñas).

Desde la perspectiva de las autoridades religiosas la educación que se brinda es integral, pues además del "estricto cumplimiento de los planes y programas de estudio determinados por la Secretaría de Educación Pública", 9 se brinda enseñanza en disciplinas deportivas como atletismo, natación, voleibol, handball, básquetbol, tiro con arco y taekwondo. Con ello se entiende que las niñas instruirán su mente estudiando secundaria y preparatoria, cultivarán su espíritu en el nombre de Dios y mantendrán su cuerpo haciendo ejercicio y distintos trabajos manuales.

Durante 2007, el brote de histeria puso en cuestionamiento la organización del internado, sus normas y exigencias, su función y el resultado que estaba dando en materia de educación. Así, mientras las autoridades de la Villa de las Niñas mandaban mensajes de honorabilidad y se empeñaban en mostrar que la suya era una institución educativa de alta calidad académica, diferentes medios informativos la revelaban como una institución de pésima educación y monjes fantasma (Blancas, 2007; Núñez, 2007).

Más adelante pude constatar que aquel apego estricto a las normas de la SEP no es real, pues la educación que se brinda no es libre y reflexiva sino limitada y excluyente de temas políticos, de sexualidad y de información del mundo exterior. Las alumnas no cuentan con libros de texto y solo se guían por los apuntes que deben de tomar durante clase.

\section{El arranque de la investigación}

Una vez que la Secretaría de Salud emitió el diagnóstico médico sobre lo ocurrido a centenares de internas y con

9 Aún antes de finalizar el 2007 así se promocionaba el internado en un portal de internet con la siguiente dirección: http://spanish.familyland.be/. Posteriormente dicho portal se cerró o se modificó. ello se exoneró a las religiosas, ${ }^{10}$ decidí iniciar el proyecto de investigación y construirlo con un enfoque reflexivo que se sustentara en los criterios de coherencia interna y viabilidad para -ahora sí- poner todos los reflectores en las internas afectadas. Pero ¿quiénes eran esas niñas y jóvenes?, ¿cómo poder llegar a ellas, si la institución se volvió hermética?

Por fortuna la revisión meticulosa del caso a través de varios medios informativos me permitió elaborar un primer mapeo de las comunidades más mencionadas de donde provenían las internas, dado que muchos padres de familia se trasladaron desde sus lejanas comunidades hasta el internado cuando el episodio de histeria se propagó por los medios.

Habían quedado boquiabiertos cuando la noticia de la histeria colectiva entró a sus casas por el televisor, mientras las evasivas telefónicas de las religiosas les imponían el impulso por llegar hasta la puerta del internado con la exigencia de ver y saber en qué situación estaban sus hijas. Sus manos aferradas al portón parecían decir que este había sido tomado como rehén para exigir con ello la presentación de sus hijas.

Expresaban un momento de mucha tensión marcado por la zozobra y la desesperación de mujeres y hombres a quienes no les importó estar largas horas y hasta días parados a las afueras del internado, aferrados al enorme portón que les impedía el acceso al interior de la institución. Acercándome por esos días (entre marzo y mayo del 2007) averigüé los primeros datos que profundicé con la información periodística. Así elaboré mi primer listado con nombres de alumnas que salían de los planteles de las Hermanas de María para volver a sus comunidades.

10 A partir del diagnóstico proporcionado por la Secretaría de Salud del Estado de México, definido como "problema psicológico de las chicas", el presidente del Colegio de Abogados Católicos de México, Armando Martínez Gómez, interpretó que las autoridades religiosas quedaban libres de cualquier responsabilidad sobre la salud de las internas (Notimex, 15/06/2007: "Exoneran a Hermanas de María en caso Villa de las Niñas"). 
Con ese listado emprendí la pesquisa realizada en varias temporadas de campo discontinuas desde el último trimestre de 2009 hasta finales de 2011. Inicié en la Montaña de Guerrero, después siguió la de Oaxaca, la de Veracruz-Puebla, el Estado de México, Hidalgo, Chiapas y Yucatán.

Para esta presentación solo me referiré al trabajo realizado en la Montaña de Guerrero, específicamente, en lugares como Tlapa, en varias comunidades del municipio de Atlamajalcingo del Monte, de Malinaltepec y de Copanatoyac. La información obtenida provino de entrevistas con 25 personas $^{11}$ (entre familiares, autoridades civiles, religiosas, médicas y exalumnas del internado) que agrupé en varias categorías: aquéllas que presenciaron el brote epidémico y enfermaron; las que lo presenciaron, pero no enfermaron; las que no estuvieron en ese momento pero que fueron internas y vivieron experiencias que, a la distancia, fueron contadas para poder explicar el fenómeno. ${ }^{12}$

Lo que a continuación presento está armado a partir de dicha información. Tiene el interés de destacar el contexto del cual surgen las ex internas de la Montaña de Guerrero, lugar que confirma los datos precisos e imprecisos con los que se le refiere por parte de diversas dependencias. Esta región empobrecida destaca entre todas las demás en las que realicé trabajo de campo, pues se advierte que efectivamente es la más pobre, la más explotada, la más afectada por el abuso y la ignorancia, la más estigmatizada; por esto mismo, es posible pensar que esa región es privilegiada por las religiosas para ha-

11 Por cuestiones de secrecía de la investigación, a algunos entrevistados se les ha cambiado el nombre.

12 La indagación se orientó siempre con una entrevista semiestructurada que abordó los siguientes temas: datos generales, familia de origen, experiencia en la Villa, atención a la salud, otros sistemas terapéuticos; el cuerpo, la higiene y sus fluidos; el trastorno psicogénico: sus nociones, explicaciones y acciones; la experiencia fuera de la Villa. cer llegar la caridad a las que se cree más necesitadas. La investigación se orientó desde una metodología básicamente cualitativa (etnografía y entrevistas a profundidad), toda vez que es la única ruta que permite dar cuenta de la compleja trama en la que los sujetos expresan sus emociones como códigos particulares que producen la intersubjetividad y dan sentido a sus vidas y a sus circunstancias, develando un contexto socio-histórico cambiante. ${ }^{13} \mathrm{Y}$ lo más importante, permite ver cómo y en qué sitio de tensión se encuentra el sujeto que narra.

El presente trabajo se expone a través de mi voz narrativa, a fin de ordenar y exponer en un marco de referencias teórico y conceptual la propia voz narrativa de un grupo amplio de ex internas a quienes se entrevistó en sus comunidades de origen.

\section{Los primeros pasos hacia la Montaña de Guerrero}

Un día de octubre del $2009,{ }^{14}$ inicié el trabajo de campo en la montaña de Guerrero con un equipo mínimo de dos arriesgadas estudiantes de antropología física. Cada vez que comentaba este interés en la ENAH, mis interlocutores me miraban con asombro y -sin decirlo- parecían reconocer una suerte de valentía que de todas maneras debía ser amparada por el único guardián que dirige con éxito toda acción en aquella zona. Me decían "debes hablar con Abel Barrera". ${ }^{15}$ Así lo hice.

13 La estrategia metodológica que pone el acento en el "punto de vista del actor" es central para explicar la enfermedad desde la experiencia y describir el significado situado etnográfica mente. En este sentido se destaca la narrativa a través de análisis detallados de entrevistas estructuradas y semiestructuradas, cuestión metodológica que he seguido en mis investigaciones teniendo como referentes a Kleinman (1988) y Groleau et al., (2006).

14 La primera temporada de campo refiere al último trimestre del 2009, que continuó durante los dos primeros meses del 2010. Es de esta experiencia de campo de donde proviene mayoritariamente la información que aquí se presenta.

15 Antropólogo de la ENAH, luchador incansable por los derechos indígenas y director de Tlachinollan, Centro de Derechos Humanos de la Montaña. 


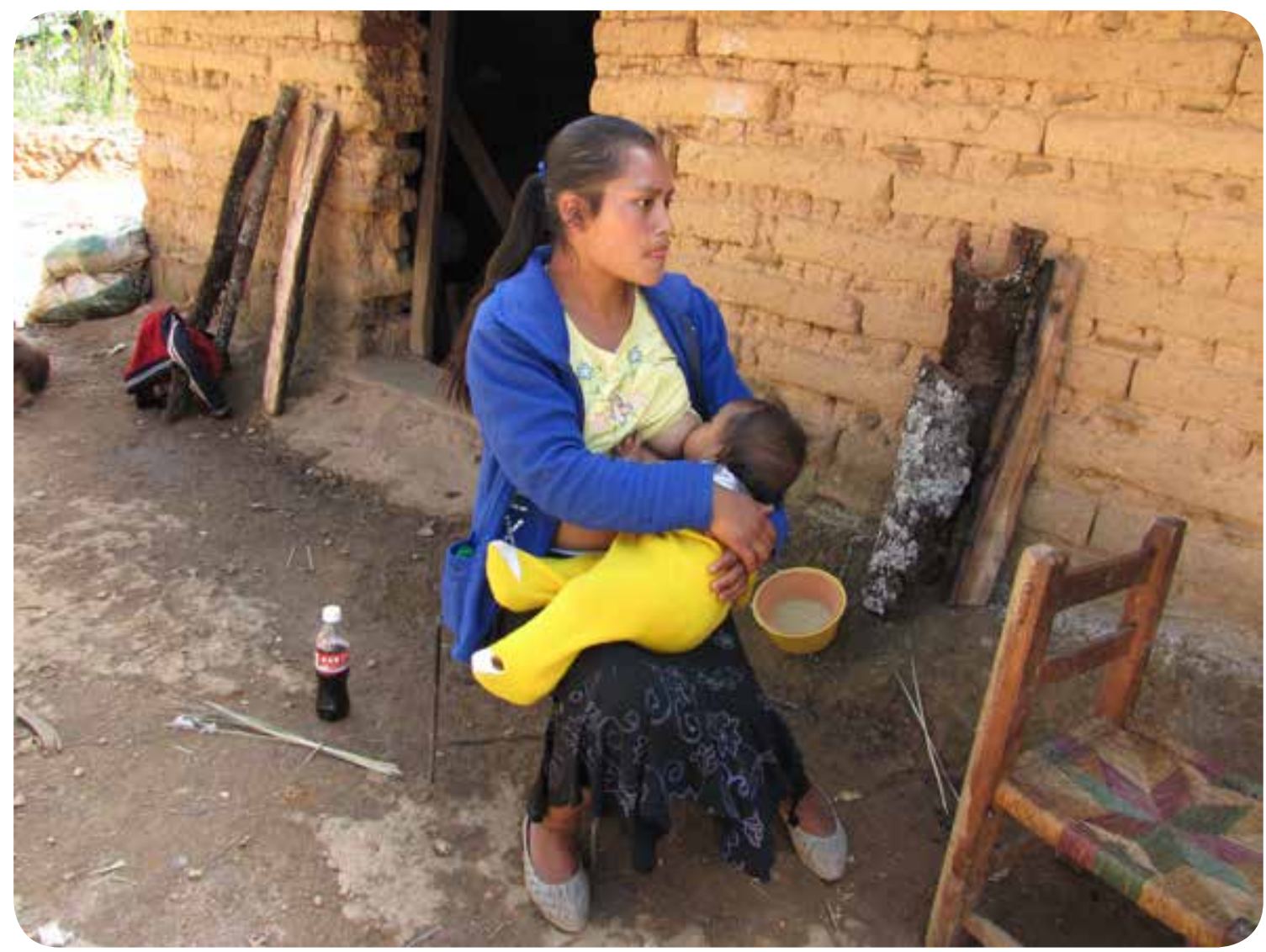

Imagen 4. Pensando la guerra en el cuerpo. Fotografía: Josefina Ramírez.

El encuentro con el Dr. Barrera en Tlapa fue la llave mágica que derribó la mayoría de las barreras que yo inconscientemente había establecido, pues todavía muy arrebatada por la necesidad de encontrar a las niñas enfermas, insistía en visitar una larga lista de comunidades. Esa lista fue reduciéndose a medida que Abel me explicaba que en muchas de las comunidades mencionadas por mí era impensable que fuera sola... o acompañada, ya que ahí estaba instalado el narcotráfico.

A partir de mi primera entrevista con el doctor Barrera, logramos contactos directos con 15 exalumnas, a las que entrevistamos ampliamente junto con sus padres. Algunas de ellas fueron localizadas gracias a que llevábamos sus nombres y su lugar de origen. A otras las contactamos a partir de la pura observación en las calles de Tlapa. Las niñas de Chalco -como les dicen en la región de la Montaña- son identificadas rápidamente por su gestualidad corporal, por su forma rígida de manejarse, por su letra y porque -según la gente- "son bien hechas". Abel afirmaba con gusto,

[...] las muchachas que han ido a estudiar a Chalco son bien vistas, porque se dice que son buenas para tra- 
bajar. Es gente muy ordenada, que capta muy bien las cosas, que es lista. Por eso Chalco agarró mucha fama y muchos padres que tenían el interés de que sus hijas estudiaran las mandaron ahí.

Al reflexionar sobre ese primer encuentro con Abel, sin pérdida de tiempo llegué al meollo del asunto: la Montaña de Guerrero provee la mayor cantidad de niñas para que vayan a estudiar a Chalco. Hay dos razones que aparecen muy visibles: por un lado, la evidente pobreza y escasas oportunidades de preparación educativa. Por el otro, la organización de los maestros de la región, cuyos integrantes afirmaban a los padres que la propuesta de las Hijas de María representaba una posibilidad para que sus hijos/as continuaran con sus estudios. ${ }^{16}$

Pero hay otras razones que se fueron develando en las diferentes entrevistas. Por ejemplo, nuestras entrevistadas hablaron de un clima de hostilidad que perturba principalmente a las mujeres, aunque es obvio que también los hombres lo sufren. No obstante, es preciso destacar la existencia de una violencia estructural que a menudo pasa desapercibida, pues forma parte de lo habitual.

Abel la describió con una oralidad cotidiana que expone los principales problemas de los habitantes de la Montaña: pobreza, cacicazgos, usos y costumbres que se complejizan con la embestida de procesos de explotación, deseos y ambiciones producidas por un neoliberalismo que se ejemplifica con el abuso hacia el otro, aunque ese otro sea un par.

Insistí en saber qué hizo Tlachinollan ante el problema suscitado en el internado. Abel Barrera me explicó que la labor de esa institución se centra en la orientación y asesoría en materia de derechos humanos y en la pro-

16 De hecho, en esta región son los maestros los encargados de trasladar a las niñas hasta Chalco, formando comités y organizándose para lograr economía y seguridad en dicha acción. moción entre la gente de la importancia de denunciar y buscar que se haga justicia. Pero que en el caso de la epidemia de histeria, Tlachinollan se enfrentó a varios hechos que le impidieron realizar acciones contundentes en relación con el problema de salud mental de las niñas y adolescentes: lo ocurrido fue en otra entidad federativa, el internado estaba involucrado con la Iglesia y eran evidentes los sentimientos encontrados entre los padres de las internas y los pobladores de Montaña, ya que, aunque sabían que ahí las niñas y adolescentes podían estudiar en forma gratuita, también estaban claros que ahí enfermaron y hubo opacidad en las razones de dicha enfermedad. En este caso, la gente no demandó esclarecer el hecho. Lamentablemente, remarcó Abel, "[...] la gente no denuncia, no solo por miedo, sino porque acá en la Montaña la justicia, como la educación, es un privilegio."

A veces no quieren denunciar porque se mezclan cosas con sus usos y costumbres. Por ejemplo, siguió exponiendo Abel:

[...] hace poco hubo un problema con una señora de un pueblo quien formó una pequeña red aquí en la Montaña con un señor de un pueblo tlapaneco. No era tan de esas grandes redes mafiosas, sino una red muy sui generis. A este señor se le hizo fácil la idea y empezó a vender niñas. Entonces se acercaba a mujeres de varias comunidades, y les decía: "Oye, consígueme niñas de 12 o 13 años que quieran trabajar". Todas indígenas tlapanecas a las que se les decía: “¿No quieres trabajar en Tlapa?, allá te van a pagar y te vamos a pagar todo, transporte, comida...o sea, es una oferta de trabajo.

No es que se las llevarán a la fuerza. iLas convencían!, afirmó Abel gesticulando un poco con ojos de impresión.

Las niñas aceptaban con la ilusión de trabajar, de salir de sus comunidades. A veces se las llevaban sin que los padres se enteraran. Las traían a Tlapa y trabajaban en una casa para luego ser llevadas a otra hasta que las llevaban 
a otras comunidades y las vendían. La trata de personas que aprovechaban los usos y costumbres, que de alguna manera se han ido descomponiendo, pues antes se pedía la mano de la muchacha y los padres del muchacho llevaban pan, café y azúcar al ir a pedirla. No se estilaba ningún tipo de relación antes del matrimonio, no había noviazgo, ni galanteo y a veces ni se conocían los muchachos. Se hacía un acuerdo entre los padres y se daba comida como dote. Ahora los padres de las muchachas llegan a pedir de 30 a 60 mil pesos por dejar que se lleven a su hija para casarla con alguien. De este modo, no había escándalo si alguien les pagaba alguna cantidad por llevarse a sus hijas y darles trabajo.

Lo que escuché en boca de Abel fueron relatos que se volvieron metáforas del horror, aquéllas que describen el poder de la tradición y las costumbres, pero también del ejército, que tras su paso siempre deja una estela de muerte, impunidad y terror. La presencia de los militares no solo rompe la armonía de las comunidades y la "aparente" tranquilidad; también actúa sobre los cuerpos, particularmente los de las mujeres desvalidas, e incluso de aquéllas que van acompañadas por sus esposos.

Pese a que no pudimos ir a las comunidades elegidas previamente, Abel nos proporcionó nombres y teléfonos de contactos que brindaron información que, en la mayoría de las veces fue detallada y veraz, pero muy escasa cuando de cifras y datos precisos se trataba. Por ejemplo, no pudieron decirme con precisión cuántas niñas salen hacia el internado cada año, de qué comunidades proceden y si después de la enfermedad hubo una baja considerable en la incorporación hacia Chalco.

De cualquier forma, en el imaginario social se apreciaba que efectivamente hubo una baja entre el 2007 y el 2008. Los padres tenían miedo, habían sido presas de la incertidumbre y en ocasiones de la culpa por enviar a sus hijas a un lugar que "creían bueno", pero que según algunos había resultado un horror.
A partir de la información primaria, que se fue profundizando a medida que tratábamos cotidianamente con las participantes y sus familiares, advertí un contexto de violencia estructural que no solo subraya la escases en rubros como salud, alimentación, seguridad, comunicación, trabajo, derechos y educación, sino que pone al desnudo relaciones jerárquicas de género que subyugan permanentemente el cuerpo de las mujeres a través -por ejemplo- de los usos y costumbres. ${ }^{17}$ Esto hace clara referencia a procesos de violencia contra la mujer que se gestan en la familia y en las tradiciones, y que tienen que ver con las relaciones de género. Dichas relaciones se develaron en la etnografía como el principal escenario de sufrimiento de las entrevistadas, del cual derivan otras violencias, y confirman lo que Segato (2003) ha afirmado sobre el género cuando subraya que este es el fundador de todas las otras formas de violencia.

\section{Respuestas ante la enfermedad}

Tantos rumores se generaron y se diseminaron fácilmente por los medios de comunicación que entre algunos padres había vergüenza: no querían decir nada, no querían que el pueblo entero se diera cuenta de que sus hijas regresaban enfermas y en cuanto llegaban a la terminal se las llevaban casi tapándoles la cabeza para que no se viera que ellas provenían de Chalco. ${ }^{18}$ La noción del contagio alertó a varias comunidades y a sus habitantes, que en un acto mezquino, o tal vez de miedo y prevención, rechazaron a las niñas y adolescentes cuyo único pecado había sido enfermarse de... iquién sabe qué!

Abel comentó que a la llegada de las jóvenes había gran conmoción y se rumoraba:

\footnotetext{
$17 \quad$ Una noticia muy actual confirma esta costumbre que atenta contra los derechos de las mujeres principalmente si son niñas, pues son presas de intercambio monetario que las coloca en la condición de "cosas" y las convierte en sujetos sin derechos. Véase "En la Montaña de Guerrero aún se venden las niñas 'casaderas' de 12-16 años, valen hasta 200 mil", disponible en: www.sinembargo.mx/31-07-2017/3274346.

18 Un distintivo del paso por el internado es el corte de cabello al ras de la barbilla.
} 
“¿Qué le hicieron a mi hija?”, “iNadie nos dice nada!”, “¿Se habrán muerto?”, “¡No tiene fuerza en las piernas, no quiere comer, no quiere decir nada!" Eso decían angustiados los padres. Entonces se empezó a escuchar que lo que tenían era brujería, que se llevaron su espíritu. Por ello ya no quisieron apoyo de nadie, no quisieron llevarlas a un hospital ni nada. Dijeron "solamente en nuestra casa va a estar segura mi hija, ya no puedo confiar en nadie, ni en las monjas, ni en las instituciones de salud pública, porque le van a hacer algo. Algo le hicieron a mi hija". Entonces se las llevaron a sus casas a curarlas con hierbas, con pócimas y mandaron llamar al rezandero.

A partir de los diferentes relatos contados por las entrevistadas pude constatar que efectivamente había vergüenza entre los padres y las ex internas. Las niñas y adolescentes vivían la enfermedad en un claroscuro que les resultaba complejo de explicar, no obstante en las primeras elaboraciones surgía la idea de haber fallado, de haber fracasado, de no lograr volver al pueblo con un certificado y con el valor agregado de haber estado en Chalco. Cuando me acerqué a algunas de las niñas y adolescentes, ellas negaron haber enfermado y enfatizaron que habían regresado porque sus padres habían ido por ellas, no porque no hubieran podido con la escuela o hubieran enfermado.

Como ya he dicho, la estigmatización y el rechazo no fueron sentidos solo por las ex internas, sino también por los padres, que al verse en esas circunstancias tuvieron que asumir ante la comunidad lo que se interpretaba como un fracaso: "Mi hija falló", "No logró un certificado", "Se volvió a lo mismo".

Recordé que, para algunos padres entrevistados, la importancia de estudiar en Chalco radicaba en el reconocimiento que significaba que sus hijas estudiaran ahí y que en su condición de internas "no andarían de locas, con las amigas o bebiendo". Lo cierto es que cuando sus hijas volvieron de Chalco se generó un escándalo que significó vergüenza y culpa para la mayoría de los padres. Posiblemente se podrían identificar otras explicaciones y consecuencias derivadas del regreso de las internas a sus comunidades, pero en términos generales los argumentos expuestos por varios padres, profesores y el mismo Abel redundan en los planteamientos expuestos.

Un relato conmovedor que destacó el sentimiento de culpa de una madre al mandar a su hija a Chalco puso de manifiesto un tejido complejo de relaciones, aspiraciones y deseos.

En Malinaltepec fuimos a buscar a Alma, maestra de preescolar y madre de Xóchitl, que regresó enferma a su pueblo. Alma, hablante de tlapaneco y español, nos otorgó la entrevista y nos hizo esperar unos minutos en su tiendita de abarrotes mientras se iba a cambiar para que empezáramos. Volvió ataviada con una hermosa blusa bordada de chaquira de Ometepec, se sentó frente a mí y empezó a decir que para ella -educadora- y su esposo -maestro normalista- era muy importante que sus hijos salieran adelante. Por eso querían que estudiaran y se prepararan bien. Comentó que tuvieron que mentir diciendo que eran pobres y que ella era ama de casa para que su hija fuera aceptada en Chalco y sus dos hijos varones ingresaran a un plantel en Guadalajara. Mencionó repetidamente que sus hijos sufrieron hambre y discriminación, pero que Xóchitl había padecido más por haberse enfermado. Sus lágrimas rodaban apresuradas cuando describió que su hija se había llenado de piojos. Para ella parecía ser una afrenta, pues eso nunca les había pasado en su pueblo.

Cuando insistí en que me explicara el porqué de su sentimiento, solo pude rescatar la idea de que por pensar que el internado era mejor que la educación de su pueblo, sus hijos sufrieron solos y ella no estuvo cerca para consolarlos. Más adelante, al entrevistar a Xóchitl, ella pudo explicar con detalle la discriminación de la que fue objeto, pues no le daban shampoo para que se bañara 


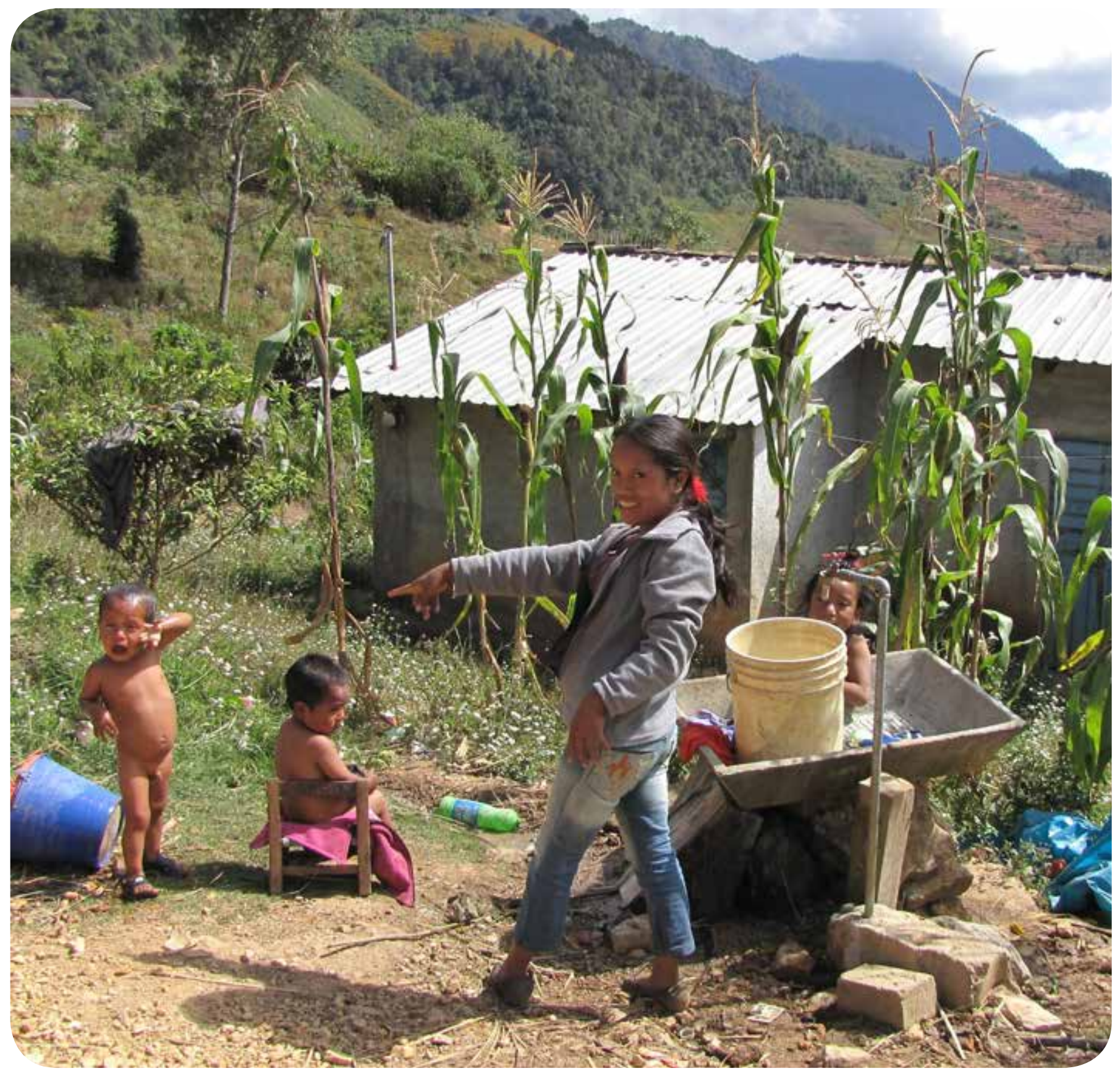

Imagen 5. La maternidad a cuestas. Fotografía: Josefina Ramírez. 
y se pudiera quitar los piojos. Xóchitl cree que sus compañeras se burlaban de ella por eso y "por ser morenita, chiquita, y hablar tlapaneco". Pero también me dejó ver que al estar en el grupo primero " $T$ " de secundaria (los grupos son de 40 niñas) tal vez recibían menos atención y cuidados que otras internas. Decía de manera pausada y en voz baja: "Las niñas de otros grupos, como el A, B, C, estaban mejor atendidas, eran más consentidas".

\section{La educación: pesar o liberación}

Desde diversos puntos de vista pude advertir que, efectivamente, quienes se han beneficiado de la educación gratuita de Chalco han sido los profesores y sus hijas, pues conforme me adentraba a otras comunidades, los habitantes más pobres reclamaban que ellos no eran los beneficiados y los maestros hacían trampa para que sus hijas quedaran elegidas. Algunos me contaron entremezclando tlapaneco y español que las hijas de los maestros se vestían con harapos y huaraches rotos, a petición de ellos mismos, para ser elegidas. Debo mencionar que los criterios de selección para estudiar en Chalco son: ser de escasos recursos, ser parte de una familia numerosa y pasar el examen de admisión.

A diferencia de Malinaltepec, en Huehuetepec encontramos más jóvenes que apenas quisieron hablar, pese a que fuimos presentadas por un habitante del pueblo que era bien conocido y había sido encomendado por Abel para que nos guiara y -si era necesario- nos apoyara traduciendo la conversación.

Al enterarme de que muchas de las internas solo hablaban su propia lengua, en algún momento supuse que en ese crisol de multiculturalidad el choque de culturas podía favorecer ciertas manifestaciones de ansiedad. Lo cierto es que estas chicas hablantes subrayaron que las monjas les prohibían hablar en su lengua, pues ellas querían enterarse de todo. Otras entrevistadas mencionaron que ser hablante de alguna lengua representaba la posibilidad de ser discriminada y maltratada, no solo por las monjas, sino por otras compañeras que se burlaban de quienes hablaban lenguas de la Montaña, no hablaban español "adecuadamente" o no lo hablaban. Una suerte de escala social se podía entrever en los relatos de las entrevistadas cuando subrayaban que la discriminación entre ellas ocurría por el color de piel y por hablar otra "lengua" pero, sobre todo, por no hablar español.

Toño nos relacionó con Sara y con Analí, ambas de 17 años, y nos presentó con su hija Cata, que dijo tener 20. Básicamente hablaban tlapaneco y no eran hijas de profesores. Una cuestión que me pareció diferente fue que las primeras se mostraban cohibidas y no querían responder a nuestras preguntas, aunque más bien me di cuenta que no querían hablar español. Mientras las entrevistaba, las escuché hablar en tlapaneco con Toño con demasiada soltura y este a su vez nos sintetizaba el comentario.

Sara y Analí tenían otra cosa en común: ambas cargaban en brazos a sus hijos de un año de edad aproximadamente. También había estado en Chalco, volvieron a su comunidad en abril del 2007 y mostraron vergüenza ante las diversas preguntas que les hice sobre su estancia en el internado y las razones de la enfermedad.

Sara fue parca, pero hablaba rápido en tlapaneco, como si pensara que hablando lento podíamos entenderla. Entre otras cosas, dijo que ella no se enfermó, pero que sus papás fueron por ella. Cuando le pregunté cómo se llevaba con sus compañeras, me dijo que le robaban sus cosas y que las madres les gritaban si ellas no entendían. Durante esta entrevista Toño agregó desenfadado: "Es que las monjas son muy estrictas. Si una vez no pudiste, va pa' juera. Como son coreanas nos califican el mexicano muy pendejo (risa) pero nosotros insistemos" (sic).

Volví a preguntar a Sara porqué creía que ocurrió la enfermedad. De una larga expresión en tlapaneco, Toño 
sintetizó con una sonrisa pícara diciendo: "Es que pus son creencias, quien sabe ¿verdad? Pero dice que echaron 'brujo'." Ante mis ojos de incomprensión subrayó: "Si pues, fue una maldad pues, a las monjas porque eran muy estrictas y entonces las niñas se rendían pues. Echaron maldad a la escuela." Y cuando le pregunté por qué las afectadas fueron las niñas, respondió con una sonrisa perspicaz: "Pues al más debel le toca, así pue..."

A lo largo de la plática pude advertir dos cosas en Sara: mostraba pena al haberse salido del internado y al saberse madre soltera. Toño preguntó en tlapaneco por el padre, recibió una respuesta en esa lengua y tradujo rápido en español: “Ese se jué, quién sabe pa' ondi, nomás aquí la dejó".

Anali corrió con una suerte parecida y con el pretexto de darle pecho a su hijo no quiso hablar. O tal vez estaba cohibida porque atrás de mí había venido a sentarse el presidente municipal que, calladito, se mantuvo ahí, observante o más bien vigilante de todo lo que hacíamos y hablábamos.

Otro día caminamos con Cata de regreso a casa de Toño. Ella dijo que quería ir a Chalco, pero que no pasó el examen. Dijo suspirando: "Me hubiera gustado". E insistió con pena: "Es que aquí nomas a uno lo maltratan. Yo quería irme desde que tenía 12, pues ya un señor grande quería pa' casarme, pero yo no quería. Yo quería irme". Bajábamos por una vereda y sus comentarios se perdían, pues ella iba más aprisa que yo, como si quisiera llegar rápido. Entonces nos encontramos con sus tres hijos. Una niña de escasos 5 años estaba encargada de bañar a sus hermanos menores de tres y dos años. Cata cogió al más chico de la mano, acabó de vestirlo y seguimos hacia su casa, que estaba cuesta arriba. De pronto se detuvo, señaló un lugar al filo del camino y me dijo: "Pasó aquí". En ese momento la miré con atención y advertí que era morena, pequeña y delgada. Tocando el sitio con su pie, enfundado en un zapato negro de plástico un poco roto que todavía le ayudaba a resistir las piedras de sus an- danzas cotidianas, me indicó el lugar y luego abrió su brazo como ala y señaló que de ese sitio se habían llevado a una joven mujer hasta esos oscuros caminos en donde la vio perderse junto con quienes la llevaban un poco a la fuerza. Alargué la mirada para buscar el camino que ella indicaba en su relato.

Lo que Cata contó y causó en mí cierta estupefacción es un hecho que, luego de algún tiempo, pasó del rumor a la aceptación. Una muchacha o varias fueron llevadas de sus comunidades a quién sabe dónde. En la región de la Montaña se sabe desde tiempo atrás que la costumbre de robarse a las mujeres para casarse posteriormente con ellas ha adoptado una variante que consiste en el robo de mujeres para llevarlas a otro lugar y ponerlas a trabajar de manera forzada. Cata quería contarlo, quería decírmelo, aunque en la inmediatez del momento no entendí muy bien por qué.

Pensé que probablemente esa información elaborada en el rumor estaba dejando huella entre las adolescentes, que ven transcurrir su vida en medio de una tierra pobre y de un destino conocido en el que se miran a sí mismas como posibles presas.

Nayeli relató en Monte Alegre que su papá le había dicho que una señora decía que unos cabrones se habían llevado a unas muchachas para venderlas. Nayeli pensaba que su papá le decía eso para asustarla, pues ella se consideraba un poco rebelde. La chica me dijo: "Yo me llevaba bien con mis papás, pero...". Con una risita nerviosa comentó:

[...] es que me da pena (risas). Me peleaba con las muchachas y me agarraba de greñas con ellas. Luego me salía de noche de mi casa, me escapaba. Iba con mis amigas a su casa y ahí hacíamos tarjetitas para nuestros compañeros. Y ya pues... de noche mi papá iba ahí y me buscaba, me regañaba. Como supo de la escuela, me dijo que me iba a mandar para allá, porque casi aquí me portaba muy mal. 
Con estos breves referentes he querido mostrar cómo la educación se busca con ansia para lograr mejorar el estatus social, para poder mantener la ideología de superación de los padres con profesión de docentes, pero también por una cuestión de sobrevivencia.

Al preguntarles por qué fueron a Chalco, inicialmente muchas chicas expresaron argumentos estereotipados sobre la educación en la región y en el internado: "Acá no enseñan bien", "los maestros no son buenos", "los maestros solo están haciendo paros", "allá la educación es de calidad".

Pero al cabo de un rato, a medida que el encuentro establecía un ambiente amable y exento de tensiones, ellas se relajaban, se sentían en confianza y eso permitía que, aunque ellas no alcanzaran a percibirlo del todo, en sus relatos mostraran un mundo hostil del que, en un acto de sobrevivencia, podían evadirse al ser aceptadas en el internado. Lo cierto es que la mayoría de ellas describieron el temor de verse inmiscuidas en la encrucijada del narcotráfico o de ser vendidas, o como diría Yosibalda, de seguir viviendo esa realidad "pasmada en el tiempo, sin avance, sin conocimientos, sin poder ser una mujer libre".

La violencia estructural alcanza el cuerpo de niños y adolescentes, de hombres y mujeres, pero sin duda es sobre estas últimas donde recae el peso de una ideología patriarcal que mata y que es una expresión de la violencia estructural que se padece en muchas regiones de México, porque no solo refiere al maltrato físico y psicológico sobre los cuerpos, sino a la falta de comida, a la ausencia de escuelas, a la carencia de agua potable y de medios para mantener la vida en salud.

\section{Reflexiones finales}

En el origen de la investigación me propuse explicar el trastorno psicogénico desde el punto de vista de aquellas internas que lo experimentaron. Para ello apunté la importancia de articular dos contextos significantes: el del internado, con sus reglas, exigencias y normas; y el de las comunidades de origen de las niñas y adolescentes, con pautas socioculturales generadas en su tradición y saber local. Si bien, en este texto el propósito no fue explicar propiamente la enfermedad y su significado, tal y como alude el objetivo de mi investigación, ${ }^{19}$ debo mencionar que al analizar con detalle toda la información generada en las diferentes regiones en donde realicé la etnografía fueron saltando algunas diferencias entre las entrevistadas.

Esas diferencias evidenciaron que, aunque todas las ex internas comparten el hecho de ser de escasos recursos, al clasificar sus relatos y a partir de la propia etnografía de sus comunidades advertí que era posible establecer una estratificación entre ellas. En este sentido, ante el brote epidémico las niñas y adolescentes de la Montaña de Guerrero respondieron con mayor temor y menor capacidad para la comprensión de lo que sucedía. Simultáneamente, el hecho develó el maltrato que estas chicas experimentaron por ser indígenas, morenas, bajitas de estatura y no hablar más que su idioma natal. ${ }^{20} \mathrm{En}$ sus relatos aparece su lugar de origen, región marginada que destacó entre todas las demás por ser la más pobre, la más explotada, la más afectada por el abuso y la ignorancia, la más estigmatizada y -por todo ello- blanco fácil de usos y abusos que afectan a sus habitantes.

Aun con una información deshilvanada, los relatos y la etnografía revelaron una generalizada violencia estructural,

19 El tema es muy complejo y ya lo he tratado en otros textos (véase Ramírez, 2014, 2017). No obstante, lo que he querido rescatar aquí es la importancia de los contextos significantes; en este caso, el de las comunidades de origen de niñas y adolescentes. Esto brindó elementos que contribuyeron a explicar el brote epidémico y los síntomas como respuestas de resistencia.

20 El grupo indígena mayoritario del internado fue oriundo de la Montaña de Guerrero y muchas niñas de esa región llegaron al internado sin hablar bien español, cuestión que representó en sí un elemento para la discriminación por parte de sus compañeras y de las religiosas (véase Ramírez, 2014b). 
experimentada por las entrevistadas y plasmada en el sometimiento de sus cuerpos, sus voluntades y sus destinos: Este sometimiento se debe a improntas impuestas por la organización patriarcal y los usos y costumbres, pero también a nuevas formas de violencia generadas por el narcotráfico y redes de trata de personas. ${ }^{21}$ En este sentido, las jóvenes de Guerrero mostraron desde sus narrativas una realidad más cruda, pero también una forma de respuesta que las expuso como sujetos frágiles, con menos posibilidades para enfrentar el contexto imperante en el internado y en consecuencia su comportamiento fue más temeroso, dócil, receptivo y susceptible de sometimiento al régimen disciplinario de esa institución. ${ }^{22}$

En el análisis de estas respuestas encontré como correlato la importancia de la educación como liberación. De esta manera veía que las jóvenes de Guerrero emigraron de un contexto de adversidad buscando la educación como alivio y liberación, pero encontraron en el internado otro cautiverio del que no podían salir y que las llevó a expresar su miedo y resistencia a través de los síntomas que, desde la biomedicina, configuraron al trastorno psicogénico (desmayos, nauseas, vómitos, dolor de cabeza, fiebre, y dolores musculares que les impedían caminar).

En mi búsqueda de explicaciones de la enfermedad, establecí un registro en el que aparecieron síntomas como: sensación de ahogo, palpitaciones, temblor de cuerpo, hormigueo, dolores de pies y rodillas, dificultad para caminar y hablar. Estos síntomas fueron configurando di-

21 En todas las comunidades de las diferentes regiones en las que trabajé, advertí que, asociados a la pobreza estaban el narcotráfico y el incremento de las redes de trata de personas. Pero vale la pena subrayar que es la marginación de las comunidades la que está implicada en el comportamiento de sus habitantes, como se puede ver en el caso que describo.

22 Esta cuestión fue evidente al compararla -por ejemplocon entrevistadas de Veracruz, que se presentaron como jóvenes activas, perspicaces, rebeldes, con más capacidades y condiciones socioculturales para negociar sus circunstancias de encierro y disciplina (véase Ramírez, 2013). versas lógicas explicativas entre las entrevistadas y sus familiares, que transitaron entre el contagio por virus, la histeria colectiva, el estrés y la brujería. ${ }^{23}$

Al tratar de explicarse el suceso y su derivado; es decir, el retorno a sus comunidades de origen sin haber logrado el certificado de estudios, tanto las entrevistadas como sus familiares emitieron juicios que aludieron a la configuración de sus propias creencias. Argumentaron que "les robaron el espíritu", las "doblegaron", les "echaron brujo" para contrarrestar la vergüenza sentida al no lograr acabar sus estudios. ${ }^{24}$

Siguiendo el análisis sofisticado que realiza Aihwa Ong (1988) sobre la posesión de espíritus de las obreras en plantas de ensamble de microchip en Malasia, ${ }^{25}$ establecimos con cierta eficacia un escenario sin duda complejo para la interpretación. Si bien hay distancia entre los escenarios, ya que mi estudio habla del internado de jóvenes y el que describe la autora es un escenario fabril

donde laboran mujeres malasias, es posible seguir su argumentación, toda vez que lo que yo estaba advirtiendo a través del análisis de los síntomas era también un proceso de resistencia cultural hacia la ideología, vigilancia y constreñimiento del cuerpo generado por el internado.

23 Ofrezco una explicación sobre estas lógicas al analizar el internado como comunidad emocional (véase Ramírez, 2017).

24 El maleficio perturba a quienes, como dijo Toño, tienen una constitución débil. Fue una manera local de explicar la enfermedad.

25 La autora indaga la expresión de malestares que alteran el orden de la fábrica y muestra cómo la biomedicina los aborda desde una lectura psicológica como "epidemia de histeria" o "padecimientos psicogénicos de masa". En el caso que analizó, tal explicación descontextualiza el sufrimiento social experimentado por mujeres jóvenes que se insertan en el mundo industrial en Malasia. El notable aporte de Ong, se da al visibilizar la lógica explicativa de las obreras al dar sentido a la posesión de espíritus como un lenguaje tradicional utilizado para rebelarse contra la autoridad fabril, que usa como medida de control la vigilancia social y corporal intensificada de la que las obreras son objeto en el capitalismo global. 


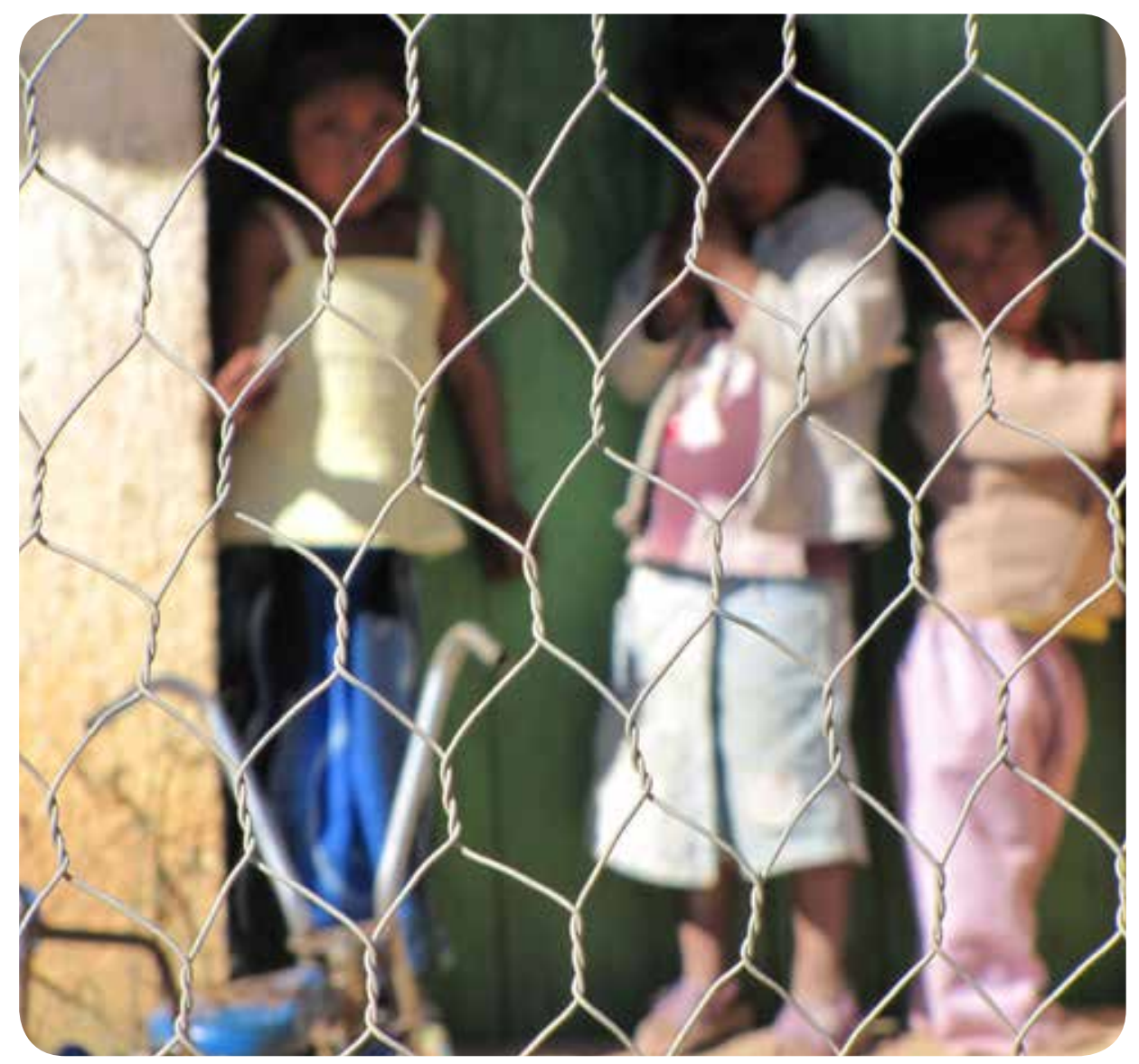

Imagen 6. Sueños que no pueden volar. Fotografía: Josefina Ramírez.

En consecuencia, como en el caso de la posesión de espíritus, los síntomas de las ex internas podían ser explicados como actos de rebelión que simbolizaron lo que no podía hablarse directamente, pero que pudo interpretarse como una renegociación de las obligaciones y derechos entre las autoridades y las alumnas (Ramírez, 2009).

La amplia y vigorosa narrativa de las entrevistadas sobre el brote epidémico describió su cuerpo como ese terreno inmediato de contradicción y sujeción, como ese espacio físico en el que confluyó el conflicto de dos sistemas de moralidad: el del internado y el de la cultura de las niñas y jóvenes que enfermaron. Asimismo, los cuerpos de esas chicas se develaron, sin que las entrevistadas lo advirtieran claramente, como el lugar de control en el que convergen los usos y costumbres, las políticas de género, la salud y las prácticas educativas.

Desde mi perspectiva, en las jóvenes de la Montaña de Guerrero se personificó la metáfora de la guerra en el 
cuerpo. Guerra que alude a la imbricación de la opresión de género y de etnia con el uso y control de los cuerpos en encierro. ${ }^{26}$

En este artículo he querido resaltar el contexto de origen de las entrevistadas diezmado por una violencia ancestral. Con algunas pinceladas de su realidad expuse lo que a mis ojos aparece como una guerra en el cuerpo de estas jóvenes, que en un acto de resistencia a ser "vendidas", a ser "robadas" o a no tener derecho a la educación, se aventuran a dejar sus comunidades para irse a un lugar desconocido que termina siendo también un martirio para el cuerpo. Desde el encierro literal que proporciona el internado hasta el cautiverio de sus cuerpos y almas (generados por un sistema de moralidad que impone un nuevo sentido a la vida de las niñas internas puesto al servicio del orden, la limpieza -no solo de sus espacios habituales sino de sus cuerpos y mentes-, en un ámbito de silencio y oración (marcado por tiempos y movimientos perfectamente cronometrados) es que encuentro la expresión del conflicto y la contradicción.

Desde el lenguaje psicológico esta expresión de conflicto y contradicción puede definirse como trastorno psicogénico, pero desde la antropología evidencia el quebranto social que se expresa como una guerra que se libra en el cuerpo de las jóvenes.

\section{Referencias}

Blancas, D. (23/04/2007). En Villa de los Niños, pésima educación y monjes fantasma, Crónica.

Dunk, P. (1989). Greek Women and broken nerves in Montreal. Medical Anthropology, 11, pp. 29-46.

Foucault, M.(1977). Vigilar y Castigar. Nacimiento de la prisión. México: Siglo XXI.

26 Si bien es posible que esta idea sea generalizada para las entrevistadas de todas las diversas comunidades, lo que ocurre con las jóvenes de Guerrero se percibe como una problemática más aguda que derivó en esta reflexión.
Goffman, E. (1994). Internados. Ensayos sobre la situación social de los enfermos mentales. México: Amorrortu Editores.

Groleau, D., Young, A., y Laurence J. K. (2006). "The McGill Illness Narrative Interview (MINI): An interview Schedule to Elicit Meanings and Modes of Reasoning Related to Illness Experience. Transcultural Psychiatry, pp. 671-691. Montreal: McGill University.

Kleinman, A. (1988). Patients and healers in the context of culture. Berkeley: University of California Press.

Lock, M. (1993). Cultivating the body: anthropology and epistemologies of bodily practice and knowledge. Annual Review of Anthropology, 22, pp. 133-55.

Lock, M., y Sheper-Hughes, N. (1996). "A Critical Interpretative Approach in Medical Anthropology: Rituals and Routines of Discipline and Dissent". En C. Sargent, Carolyn F., y Thomas M. Johnson (eds.). Medical Anthropology: a Handbook of Theory and Method, pp. 47-72. London: Greenwood Press.

Martin, E. (1992). The woman in the body. A cultural Analysis of Reproduction. Boston: The Bacon Press.

Menéndez, E., y Di Pardo, R. (1996). De algunos alcoholismos y algunos saberes. Atención primaria y proceso de alcoholización. México: Ciesas.

Núñez, M. A. (21/06/2007). Al amparo de Marta Fox: monjas en explotación infantil, La Jornada.

Ong, A. (1988). The production of possession: Spirits and the Multinational Corporation in Malaysia. American ethnologist, 15, pp. 28-10.

Ramírez, J. (2017). El Internado de Villa de las Niñas como comunidad emocional: disciplina y control de los cuerpos en el encierro. Revista de Estudios Sociales, Bogotá: Universidad de los Andes.

(2014a). "Cuerpos sujetos y cuerpos sujetados. Análisis antropológico del trastorno psicogénico de internadas en una institución religiosa en México". En Rocío Enríquez y Oliva López (Coords.) Las emociones en el marco de las ciencias sociales: Perspectivas interdisciplinarias, [Vol.] (pp. ). México: FES Iztacala - UNAM / Universidad Jesuita de Guadalajara ITESO.

(2014b). La construcción sociocultural del miedo y el coraje en un internado de religiosas. Una narración personal contada con necesidad. Revista Latinoamericana sobre el Cuerpo y las Emociones, 14. Recuperado de http://www.relaces.com.ar/index.php/ relaces/article/viewFile/286/197

(2013). De la curiosidad al miedo. Experiencia corporal de un grupo de internas ante el encierro y la disciplina, en una institución educativa religiosa. Estudios de Antropología Biológica, XVI, pp. 623-651. 
(2012). El trabajo docente en los márgenes y sus efectos en la salud. Percepción de profesores de un internado de religiosas del Estado de México. Cuicuilco, 53, pp. 11-37. Recuperado de http://www.redalyc.org/pdf/351/35125832002.pdf

(2010a). El desarrollo de una antropología física crítica y la generación de antropólogos físicos situados. México: Memorias del Primer Congreso Nacional de Antropología Social y Etnología de México.

(2010). El estrés como metáfora. Estudio antropológico con un grupo de operadoras telefónicas. México: INAH-CONACULTA (Colección Científica 558).

(2009). “Los efectos del poder en el cuerpo. Explicación sociocultural de la epidemia de histeria ocurrida a cientos de adolescentes internadas en una institución religiosa en México". Memorias LASA - XXVIII International Congress Rethinking inequalities.
Scheper-Hughes, N., y Lock, M. (1987). “The Mindful Body: A Prolegomenon to Future Work in Medical Anthropology". Medical Anthropology Quaterly, 1, pp. 6-41.

Segato, R. L. (2003). Las estructuras elementales de la violencia. Bernal: Universidad Nacional de Quilmes.

Van Schaik, E. (1988). Paradigms Underlying the Study of Nerves as a popular Illness Term in Eastern Kentucky. Medical Anthropology, 11, pp. 15-28.

Young, A. (1982). The Anthropology of Illness and Sickness. Annual Review of Anthropology, 11, pp. 257-285. 


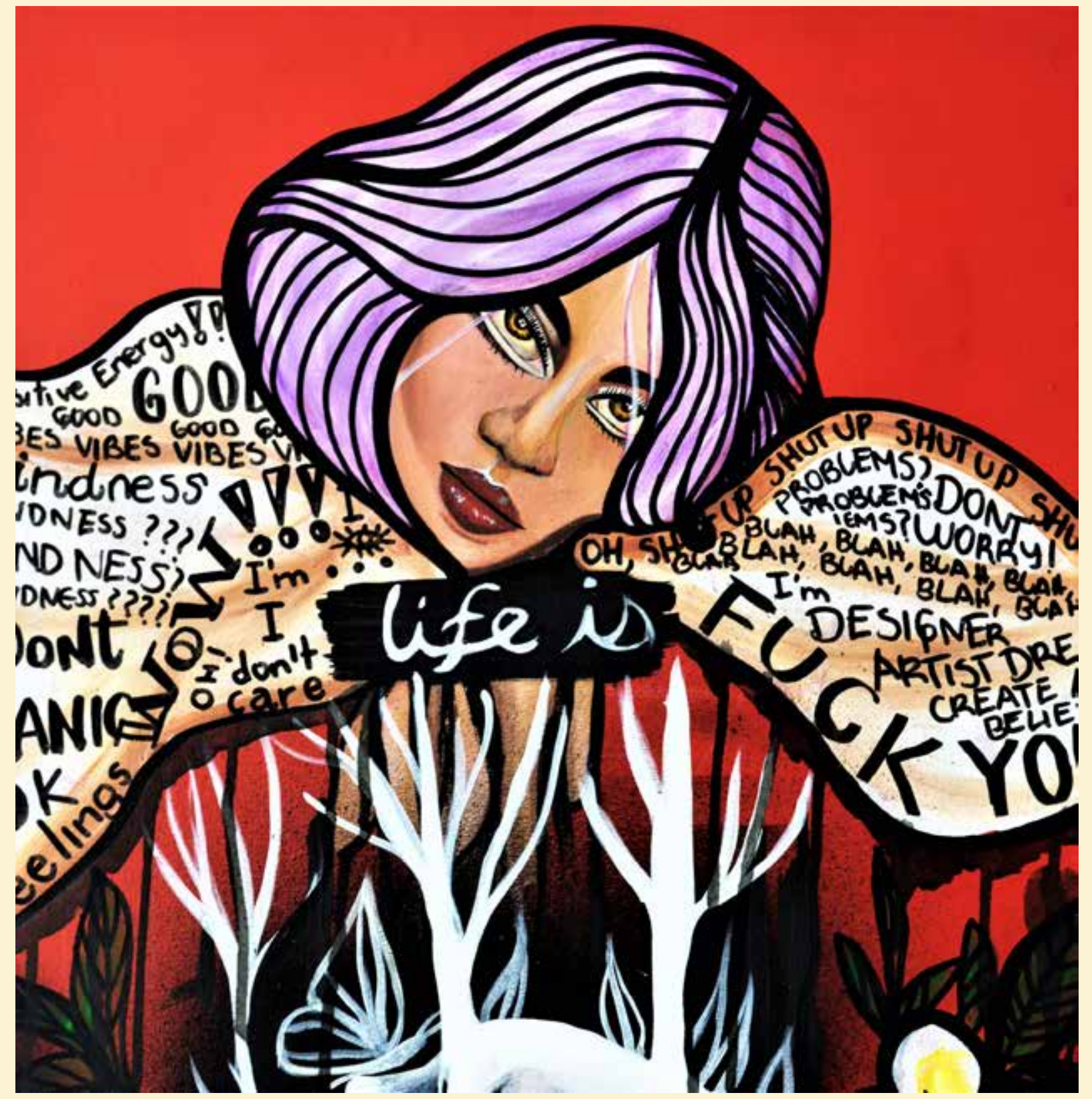

Life is...(Dimarc Ayala, 2019) Acrílico sobre lienzo 